\title{
Evaluation of Long-term Outcomes and Prediction of Failure Rate of Endoscopic Third Ventriculostomy in Less Than 2 Years Children
}

\author{
Hasanreza Mohammadi ${ }^{\circledR}$, Masoud Sadat $^{1 *(\infty)}$, Hamidreza Khayat Kashani $^{1}$ \\ ${ }^{1}$ Department of Neurosurgery, Imam Hossein Hospital, Shahid Beheshti University of Medical Sciences, Tehran, Iran
}

\begin{abstract}
Background:The study carried out to assess long-term outcomes of endoscopic third ventriculostomy (ETV) on less than two years of hydrocephalous children and to determine prognostic factors of ETV success in this population.

Methods: our study was a retrospective cohort study carried out on 40 hydrocephalus children who underwent ETV surgery. Clinical data retrieved from patient's medical records, and we did an active follow-up. We used Kaplan-Meier and life-table approaches to assess 6 months success rate of ETV. We also used multiple cox regression to determine prognostic factors associated with success. Moreover, the ROC curve analysis was used to assess how ETV success score (ETVSS) can predict the possibility of ETV failure.

Results: The mean age of patients at surgery time was $7.8( \pm 7.8)$ months, and $60 \%$ were male. The mean failure time of ETV was 4.5 months, and the most common etiology was aqueduct $(27.0 \%)$. According to our finding age at surgery time (hazard ratio $[\mathrm{HR}]=2.2,95 \% \mathrm{Cl}=1.1,3.4$ ) and birth age $(\mathrm{HR}=4.4,95 \% \mathrm{Cl} 1.1,17.2)$ were the main factors associated with ETV failure. We also observed, statistically lower $\mathrm{HR}$ for patients with aqueduct etiology $(\mathrm{HR}=0.1,95 \% \mathrm{Cl}=0.01,0.9)$. Moreover, the area under the ROC curve was estimated at 76.1, illustrating partial validity to predict ETV failure in the study population.

Conclusion: According to our findings, ETV could suggest treating Hydrocephaly in young kids with particular attention on over 6-month patients and those who were mature at birth. However, more studies are required to confirm our findings.

Keywords: Obstructive hydrocephalus; Aqueduct stenosis; Endoscopic third ventriculostomy; Infant; Pediatric neurosurgery.
\end{abstract}

\author{
*Correspondence to \\ Masoud Sadat, \\ Department of Neurosurgery \\ EmamHossien Hospital, \\ ShahidBeheshti University of \\ Medical Sciences, Tehran, Iran. \\ Fax: +982177557069, Tel: \\ +98912857960, \\ Email: Dr.msadat2020@yahoo. \\ com
}

Published online March 10,

2020

Citation: Mohammadi H, Sadat M, Khayat Kashani H. Evaluation of Long-term Outcomes and Prediction of Failure Rate of Endoscopic Third Ventriculostomy in Less Than 2 Years Children. Int Clin Neurosci J. 2020;7(2):66-70. doi:10.34172/icnj.2020.04.

\section{Introduction}

Hydrocephalus is one of the most prevalent disorders relating to the cerebrospinal fluid (CSF) motion. ${ }^{1}$ Hydrocephalus referred to the problem in production, fellow, and absorption of CSF, which leads to an increase in CSF within the intracranial compartment. ${ }^{2}$ It has a considerable incidence in the Eastern Mediterranean Region of WHO. It has estimated that annually around 38000 new cases of hydrocephalus diagnosed in this region. ${ }^{1}$

In recent decades several approaches, including ventricular shunts and endoscopic third ventriculostomy (ETV), have been introduced as a treatment of hydrocephalus. ${ }^{3}$ Although ventricular shunts are known as the standard treatment of hydrocephalus, this approach is not free from complications. Moreover, the failure rate of the ventricular shunt is slightly high, and it reported between $30 \%-80 \%$ in previous studies. ${ }^{4,5}$

On the other hand, endoscopic techniques have been developed in recent decades and provided desirables outcomes. Comparing to ventricular shunts, the risk of infection and malfunction is lower in ETV. Also, ETV is more accessible in developing countries and imposes less cost to both patients and the health system. Many studies have fully supported. ${ }^{6,7}$ Although the effectiveness of ETV in adult and older children, the usefulness of using ETV in infants, which mostly suffer from secondary hydrocephalus due to infection and myelomeningocele, is still challenging. As the number of younger than 6-month hydrocephalus patients considered in our setting, we

(C) 2020 The Author(s). This is an open access article distributed under the terms of the Creative Commons Attribution License (http:// creativecommons.org/licenses/by/4.0/), which permits unrestricted use, distribution, and reproduction in any medium, provided the original work is properly cited. 
aimed to compare the efficacy of ETV between infants and older children. In the current study, we assessed prognosis and long-term complications of ETV in less than two-year children.

\section{Materials and Methods}

The current study was a retrospective study carried out on 40 less than 2 years of hydrocephalus patients who were referred to the Mofid and Imam-Hossein hospitals in Tehran from 2013 to 2018. Clinical information of study participants, including date of ETV surgery, age at the time of ETV surgery, sex, and cause of hydrocephalus extracted from medical records. We also estimated ETV success score (ETVSS) for each participant through the information of medical records and patients visits by a neurosurgery resident. We followed patients actively through telephone or face to face interviews, and during the interview, they asked about the increase or improvement of Intra Cranial pressure raising symptoms (ICP), presence of neurologic disorders, growth status of the patient, re-ETV, or need to ventricular shunt, vital status, and cause of death. Death after surgery due to an increase of ICP and need to re-ETV or shunt placement along with worsening of clinical signs defined as the failure of ETV. The decision for re-operation made when the increase in intracranial pressure besides enlargement of ventricles observed in post-operative images compare to pre-operative ones.

\section{Statistical Analysis}

We reported mean and standard deviation to report distribution of continuous variables across comparing groups. We also used the proportion and 95\% CI for dichotomous variables. Kaplan-Meier and life table approaches were applied to report the survival time of ETV. We also used a multiple Cox regression to investigate the association between failure of ETV and the investigated variables.

Furthermore, we draw a ROC curve to determine the best cut-off point for ETVSS in order to predict the success of ETV, and for the estimated cut-point sensitivity and specificity was calculated. The cut-point was estimated based on the highest sensitivity and specificity. All statistical analysis was carried out by SPSS version 22.0.

\section{Results}

The mean age $( \pm \mathrm{SD})$ of study participants was $7.8( \pm 7.8)$ month, and $60.0 \%$ of whom were men. Aqueduct (25.0\%) was the most prevalent etiology of hydrocephalus, while myelomeningocele had the lowest proportion (10.0\%). $22.5 \%$ of the patient was born pre-term, and mean of head circumstances at birth and ETV time were 34.1 and 43.6, respectively. Finally, the mean of pre-operative ETVSS as estimated at $57.6( \pm 12.4)$ (Table 1).

The success rate of ETV was reported 70.3\% (95\% CI, $49.4,73.9)$ for less than the 6-month group, while it was 92.3\% (95\% CI, 74.1, 98.8) and the observed difference was statistically significant $(P=0.047)$ (Figure 1$)$. We also observed a partially higher success rate in females $(81.2 \%)$ comparing to male (75.0\%). However, no statistical difference observed $(P=0.790)$. Success rate of ETV 6 month after surgery in pre-term infants was $60.0 \%$ (95\% CI, 25.2, 82.7) which was considerably lower than term ones (success rate $=86,6 \%, 95 \% \mathrm{CI}, 68.2,94.7)(P=0.028)$ (Figure 2). We also observed the highest 6-month survival of ETV in patients with aqueduct etiology (90.1\%, 95\% $\mathrm{CI}, 50.8,98.6)$, and myelomeningocele etiology had the lowest success rate (success rate $=50.0 \%, 95 \%$ CI, 5.7,

Table 1. Study Participants Characteristics

\begin{tabular}{|c|c|c|c|}
\hline Variable & Subgroups & $\mathbf{n}$ & $\%$ \\
\hline \multicolumn{4}{|l|}{ Gender } \\
\hline & Male & 24 & 60.0 \\
\hline & Female & 16 & 40.0 \\
\hline \multicolumn{4}{|c|}{ Age group } \\
\hline & Under 6 months & 27 & 67.5 \\
\hline & 6-24 months & 13 & 32.5 \\
\hline \multicolumn{4}{|l|}{ Etiology } \\
\hline & Idiopathic & 8 & 20.0 \\
\hline & Dandy walker & 10 & 25.0 \\
\hline & Aqueduct & 11 & 27.5 \\
\hline & Myelomeningocele & 4 & 10.0 \\
\hline & Meningitis & 7 & 17.5 \\
\hline \multicolumn{4}{|l|}{ Birth age } \\
\hline & Pre-term & 10 & 25.0 \\
\hline & Term & 30 & 75.0 \\
\hline
\end{tabular}




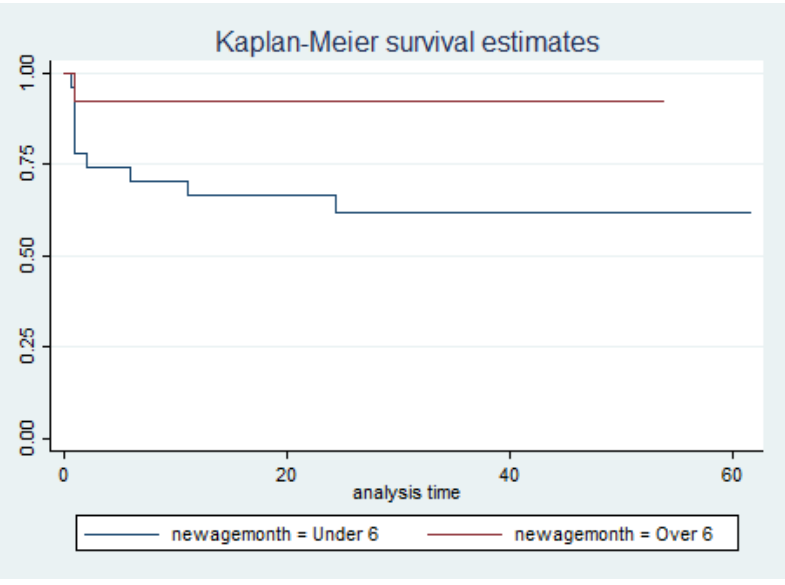

Figure 1. Success Rate of ETV by Age Groups

84.4) $(P=0.109)$ (Table 2).

ETVSS the best cut-point estimated according to highest sensitivity and specificity at 55 and the estimated cut-point sensitivity and specificity of ETVSS for the success of ETV was $62.0 \%$ and $63.6 \%$, respectively. Area under curve (AUC) was also 76.1 (95\% CI, 61.4, 90.8) (Figure 3 ).

We also assessed the adjusted effect of the investigated variables through multiple cox regression. The hazard ratio for pre-term born estimated at 4.4 (95\% CI, 1.1, 17.2), which was statistically significant $(P=0.029)$. We also observed a statistically significant association between age at ETV and the success rate of ETV (hazard ratio $[\mathrm{HR}]=2.2,95 \% \mathrm{CI}=1.1,3.4)$. Moreover, over 55 ETVSS scores increased the hazard of ETV failure by 2.1. However it was not statistically significant (95\% CI, $0.8,3.2)(P=0.067)$. The hazard ratio of ETV failure for

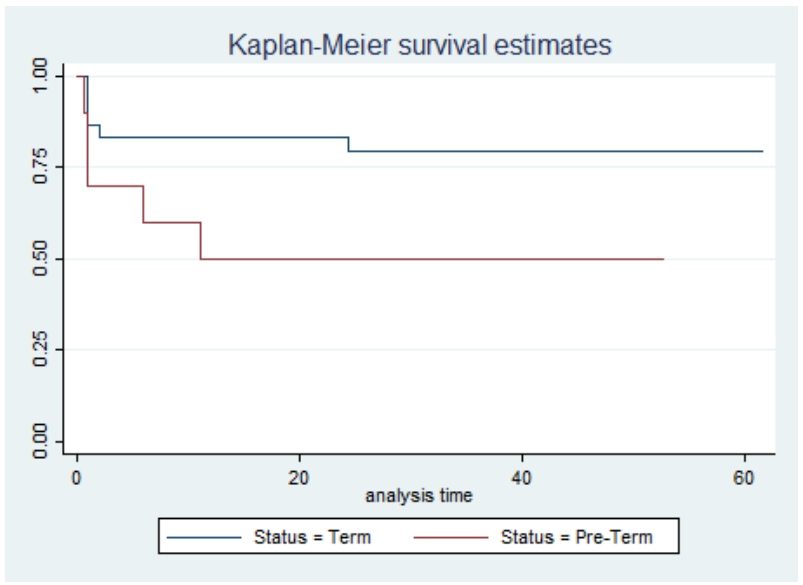

Figure 2. success Rate of ETV by Birth Age Group (Term/Preterm)

Aqueduct etiology was significantly lower than patients with Dandy-Walker syndrome etiology $(\mathrm{HR}=0.1,95 \%$ CI, 0.01, 0.9) (Table 3).

\section{Discussion}

In this study, we aimed to compare the efficacy of ETV on over and under 6-month children who diagnosed with hydrocephalus at Imam Hossein and Mofid hospital from 2013 to 2018. The success rate of ETV for less than 6 months and over 6-month children was 70.3 and 92.3, respectively. We also demonstrated a significantly lower success rate for those patients who were born pre-term. Etiology and ETVSS were other main prognostic factors for ETV success.

The overall success rate of ETV was $80.0 \%$, and it provided significantly better outcomes in older children. Beuriat et al have reported a $70.0 \%$ success rate, which

Table 2. Success rate of ETV Across Age, Sex, Etiology and Birth Age

\begin{tabular}{|c|c|c|c|c|}
\hline Variable & Subgroups & Success Rate & $95 \% \mathrm{Cl}$ & $P$ Value \\
\hline \multicolumn{5}{|l|}{ Gender } \\
\hline & Male & 75.0 & $52.6,87.9$ & \\
\hline & Female & 81.2 & $52.4,93.5$ & 0.790 \\
\hline \multicolumn{5}{|c|}{ Age group } \\
\hline & Under 6 months & 70.3 & $49.4,73.9$ & \\
\hline & 6-24 months & 92.3 & $74.1,98.8$ & 0.047 \\
\hline \multicolumn{5}{|l|}{ Etiology } \\
\hline & Idiopathic & $87.5 \%$ & $38.7,98.1$ & \\
\hline & Dandy walker & 60.0 & $25.2,82.7$ & \\
\hline & Aqueduct & 90.1 & $50.8,98.6$ & \\
\hline & Myelomeningocele & 50.0 & $5.7,84.4$ & \\
\hline & Meningitis & 71.4 & $13.2,97.8$ & 0.109 \\
\hline \multicolumn{5}{|l|}{ Birth age } \\
\hline & Pre-term & 60.0 & $25.2,82.7$ & \\
\hline & Term & 86.6 & $68.2,94.7$ & 0.028 \\
\hline
\end{tabular}


Table 3. Association Between ETVSS and ETV Success Rate Adjusted for Age, Sex, Birth Age and Etiology

\begin{tabular}{|c|c|c|c|c|}
\hline Variable & Subgroups & Hazard Ratio & $95 \% \mathrm{Cl}$ & $P$ Value \\
\hline \multicolumn{5}{|l|}{ Gender } \\
\hline & Male & 1 & & \\
\hline & Female & 1.3 & $0.3,5.1$ & 0.618 \\
\hline \multicolumn{5}{|c|}{ Age group } \\
\hline & 6- 24 months & 1 & & \\
\hline & Under 6 months & 2.2 & $1.1,3.4$ & 0.048 \\
\hline \multicolumn{5}{|l|}{ Etiology } \\
\hline & Dandy walker & 1 & & \\
\hline & Idiopathic & 0.2 & $0.02,1.7$ & 0.149 \\
\hline & Aqueduct & 0.1 & $0.01,0.9$ & 0.046 \\
\hline & Meningitis & 0.5 & $0.1,2.8$ & 0.486 \\
\hline & Myelomeningocele & 1.5 & $0.2,8.3$ & 0.600 \\
\hline \multicolumn{5}{|l|}{ Birth age } \\
\hline & Term & 1 & & \\
\hline & Pre-term & 4.4 & $1.1,17.2$ & 0.029 \\
\hline \multicolumn{5}{|l|}{ ETVSS } \\
\hline & Over 55 & 1 & & \\
\hline & Under 55 & 2.1 & $0.8,3.2$ & 0.067 \\
\hline
\end{tabular}

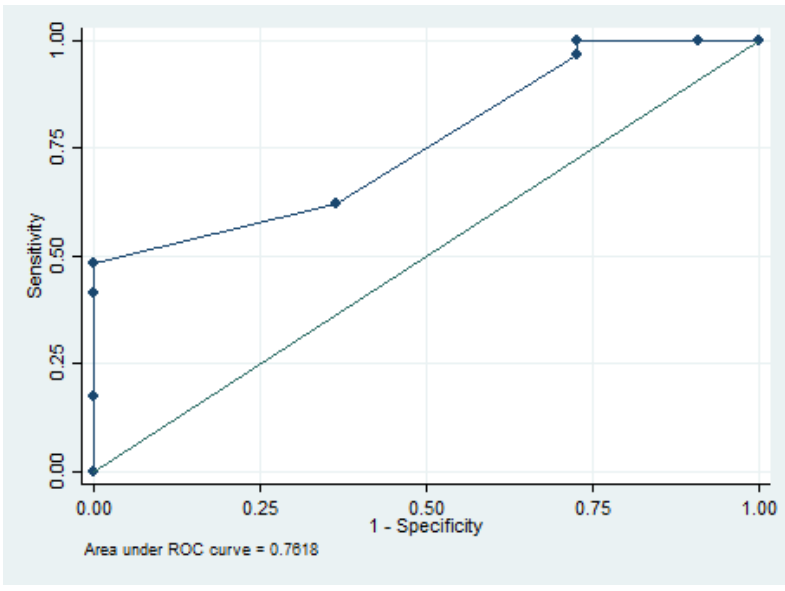

Figure 3. ETVSS ROC Curve to Estimate the Best Cut-Point According to Highest Sensitivity and Specificity

is inside of our findings. ${ }^{7}$ Several other studies reported higher than $70 \%$ success rate for ETV in children who support our study results. ${ }^{8-11}$

Age at ETV has previously shown as a prognostic factor of ETV success in several studies. Most studies reported a reduced success rate in younger children and in the recent study in support of previous findings we reported a significantly higher success rate for older patients. $^{12-15}$ Several pathological mechanisms have already introduced for the lower success rate of ETV in younger patients. ${ }^{16,17}$ Poor absorption of CSF is one the most critical factor which seems is responsible for the failure of ETV. However, Wagner et al suggested that the formation of new arachnoid may play a vital role in this regard, even more, critical than poor absorption of CSF. It has argued that a higher tendency to new arachnoid membranes in younger patients may explain the higher ETV failure among them. ${ }^{17}$

Furthermore, we found that patients with preterm birth had a lower success rate comparing those patients who were mature at birth time. As it mentioned absorption of CSF is one the most critical factor in terms of ETV success rate, and it seems lower absorption capacity in premature infants due to less development of the central nervous system is the main reason to justify this difference.

The most favorable outcome was observed in patients with aqueduct stenosis etiology, while the lowest success rate observed in Dandy-Walker syndrome and myelomeningocele etiologies. It has already shown that the overall success rate in aqueduct stenosis is pretty higher; however, other studies reported no difference regarding etiology. ${ }^{11-18}$

We also used ETVSS as a predictor of the ETV success rate, and it has illustrated that it could consider as a moderate predictor for prognosis of ETV surgery in children. The best cut-off point for ETVSS estimated at 55.0, according to the highest sensitivity and specificity. We observed inconsistency in our findings compares to the previous studies. García et $\mathrm{al}^{8}$ reported high validity for ETVSS to predict ETV failure among older than 1 year children, eight while Kulkarni et al showed that ETVSS could not be used as a valid measure for ETVSS prognosis. ${ }^{19}$ There are some other studies, which reported low sensitivity and specificity for ETVSS. As these studies 
have carried out on patients in different age groups, it seems to age at ETV time is also an essential factor for the validity of ETVSS, and among older children, ETVSS is the more valid index to predict success rate.

The current study carried out on all children who were admitted with hydrocephalus at 2 distinctive neurosurgery centers in Tehran for 5 years. This is the first research in which we compared the long-term outcome of ETV surgery in Iranian children. The same surgeon has operated all patients and in the same condition to remove the effect of surgeon proficiency and difference in provided care. However, there are some limitations which could be regarded to generalize our findings. The low sample size was the main limitation of our study that reduces the generalizability of our findings. Moreover, we followed the patient's complications and outcomes retrospectively through medical records, and this approach could affect data quality.

In conclusion, ETV provides more favorable outcomes in older children, and those who were mature at birth and applying this surgery for younger children suffering from hydrocephalus must use with some considerations. However, it seems a multi-center and prospective study with a larger sample size required for more deterministic decision-making.

\section{Acknowledgments}

This study was part of the thesis of the corresponding author and funded by Shahid Beheshti University of Medical Sciences. The authors would like to thank all of our colleagues at the Imam Hossein hospital, who helped us in data collection.

\section{Conflict of Interest Disclosures}

The authors declare that they have no conflict of interests.

\section{Ethical Statement}

Reassurance to patients that all of their information will be secret and ETV is an accepted safe treatment.

\section{References}

1. Dewan MC, Rattani A, Mekary R, Glancz LJ, Yunusa I, Baticulon RE, et al. Global hydrocephalus epidemiology and incidence: systematic review and meta-analysis. J Neurosurg. 2018:1-15. doi: 10.3171/2017.10.jns17439.

2. Rekate HL. The definition and classification of hydrocephalus: a personal recommendation to stimulate debate. Cerebrospinal Fluid Res. 2008;5:2. doi: 10.1186/1743-8454-5-2.

3. Deopujari CE, Karmarkar VS, Shaikh ST. Endoscopic third ventriculostomy: success and failure. J Korean Neurosurg Soc. 2017;60(3):306-14. doi: 10.3340/jkns.2017.0202.013.

4. Reddy GK, Bollam P, Caldito G, Guthikonda B, Nanda A. Ventriculoperitoneal shunt surgery outcome in adult transition patients with pediatric-onset hydrocephalus. Neurosurgery. 2012;70(2):380-8. doi: 10.1227/NEU.0b013e318231d551.

5. Vinchon M, Rekate H, Kulkarni AV. Pediatric hydrocephalus outcomes: a review. Fluids Barriers CNS. 2012;9(1):18. doi: 10.1186/2045-8118-9-18.

6. Zandian A, Haffner M, Johnson J, Rozzelle CJ, Tubbs RS, Loukas M. Endoscopic third ventriculostomy with/without choroid plexus cauterization for hydrocephalus due to hemorrhage, infection, Dandy-Walker malformation, and neural tube defect: a meta-analysis. Childs Nerv Syst. 2014;30(4):571-8. doi: 10.1007/s00381-013-2344-9.

7. Beuriat PA, Szathmari A, Grassiot B, Plaisant F, Rousselle C, Mottolese C. Role of endoscopic third ventriculostomy in the management of myelomeningocele-related hydrocephalus: a retrospective study in a single French institution. World Neurosurg. 2016;87:484-93. doi: 10.1016/j. wneu.2015.07.071.

8. García LG, López BR, Botella GI, Páez MD, da Rosa SP, Rius F, et al. Endoscopic Third Ventriculostomy Success Score (ETVSS) predicting success in a series of 50 pediatric patients. Are the outcomes of our patients predictable? Childs Nerv Syst. 2012;28(8):1157-62. doi: 10.1007/s00381-012-1836-3.

9. Kulkarni AV, Sgouros S, Constantini S. International Infant Hydrocephalus Study: initial results of a prospective, multicenter comparison of endoscopic third ventriculostomy (ETV) and shunt for infant hydrocephalus. Childs Nerv Syst. 2016;32(6):1039-48. doi: 10.1007/s00381-016-3095-1.

10. Navarro R, Gil-Parra R, Reitman AJ, Olavarria G, Grant JA, Tomita T. Endoscopic third ventriculostomy in children: early and late complications and their avoidance. Childs Nerv Syst. 2006;22(5):506-13. doi: 10.1007/s00381-005-0031-1.

11. Faggin R, Bernardo A, Stieg P, Perilongo G, d'Avella D. Hydrocephalus in infants less than six months of age: effectiveness of endoscopic third ventriculostomy. Eur J Pediatr Surg. 2009;19(4):216-9. doi: 10.1055/s-0029-1202282.

12. Jernigan SC, Berry JG, Graham DA, Goumnerova L. The comparative effectiveness of ventricular shunt placement versus endoscopic third ventriculostomy for initial treatment of hydrocephalus in infants. J Neurosurg Pediatr. 2014;13(3):295-300. doi: 10.3171/2013.11.peds13138.

13. Kulkarni AV, Drake JM, Mallucci CL, Sgouros S, Roth J, Constantini S. Endoscopic third ventriculostomy in the treatment of childhood hydrocephalus. J Pediatr. 2009;155(2):254-9.e1. doi: 10.1016/j.jpeds.2009.02.048.

14. Kulkarni AV, Drake JM, Kestle JR, Mallucci CL, Sgouros S, ConstantiniS. Predicting who will benefit from endoscopic third ventriculostomy compared with shunt insertion in childhood hydrocephalus using the ETV Success Score. J Neurosurg Pediatr. 2010;6(4):310-5. doi: 10.3171/2010.8.peds103.

15. Koch-Wiewrodt D, Wagner W. Success and failure of endoscopic third ventriculostomy in young infants: are there different age distributions? Childs Nerv Syst. 2006;22(12):1537-41. doi: 10.1007/s00381-006-0191-7.

16. Oi S, Di Rocco C. Proposal of "evolution theory in cerebrospinal fluid dynamics" and minor pathway hydrocephalus in developing immature brain. Childs Nerv Syst. 2006;22(7):662-9. doi: 10.1007/s00381-005-0020-4.

17. Wagner W, Koch D. Mechanisms of failure after endoscopic third ventriculostomy in young infants. J Neurosurg. 2005;103(1 Suppl):43-9. doi: 10.3171/ped.2005.103.1.0043.

18. Kunz U, Goldmann A, Bader C, Waldbaur H, Oldenkott P. Endoscopic fenestration of the 3rd ventricular floor in aqueductal stenosis. Minim Invasive Neurosurg. 1994;37(2):42-7. doi: 10.1055/s-2008-1053447.

19. Kulkarni AV, Riva-Cambrin J, Browd SR. Use of the ETV Success Score to explain the variation in reported endoscopic third ventriculostomy success rates among published case series of childhood hydrocephalus. J Neurosurg Pediatr. 2011;7(2):143-6. doi: 10.3171/2010.11.peds10296. 